\title{
Analysis of River Blocking Induced by a Debris Flow
}

\author{
Lijuan Wang, ${ }^{1,2}$ Ming Chang, ${ }^{1}$ Xiangyang Dou, ${ }^{1}$ Guochao Ma, ${ }^{1,2}$ and Chenyuan Yang ${ }^{1}$ \\ ${ }^{1}$ State Key Laboratory of Geohazard Prevention and Geoenvironment Protection, Chengdu University of Technology, \\ Chengdu 610059, China \\ ${ }^{2}$ Sichuan Academy of Safety Science and Technology, Chengdu 610045, China
}

Correspondence should be addressed to Ming Chang; changmxq@126.com

Received 13 June 2017; Accepted 22 August 2017; Published 28 September 2017

Academic Editor: John A. Mavrogenes

Copyright (C) 2017 Lijuan Wang et al. This is an open access article distributed under the Creative Commons Attribution License, which permits unrestricted use, distribution, and reproduction in any medium, provided the original work is properly cited.

Both the Wenchuan earthquake on May 12, 2008, and the Lushan earthquake on April 12, 2013, produced many coseismic landslides along the Nanya River in Shimian City. Subsequent debris flows that initiated from these landslides and are triggered by intense rainfall become the secondary hazard in the years after the earthquake; in particular, some debris flows led to a serious river blocking event. For example, the Guangyuanbao debris flow which occurred on July 04, 2013, partly blocked the Nanya River, presenting a major threat to the national highway and residential areas. To analyze the pattern of landslide damming, we analyzed numerical simulations of the movement characteristics of the Guangyuanbao debris flow using rainfall intensities with varying recurrence periods of 5,20 , and 50 years. The accuracy of the spreading of the numerical simulation is about $90 \%$. The simulation indicated a small volume of sediment entering the river for a rainfall under 5 -year return period. A debris flow induced by rainfall under 20 year return period partly blocked the river, while rainfall under 50-year return period has potential to block the river completely. This proposed analysis of river blocking induced by a debris flow could be used for disaster prevention in earthquake-stricken area.

\section{Introduction}

Debris flows represent one of the most common geological hazards in mountainous areas, usually carrying large volumes of sediment threat to roads, farmlands, settlements, human life, and property [1-3]. On May 12, 2008, a large amount of coseismic landslides was produced by Wenchuan earthquake with a magnitude of Ms 7.9, which provided ample loose material needed for the occurrence of debris flows $[4,5]$. On April 12, 2013, Lushan earthquake, with a magnitude of Ms 7.0, induced a lot of land sliding along the southern segment of the Longmen Shan fault zone [6]. After the earthquake, highintensity rainfall transformed parts of the coseismic landslide material into debris flows [7-9]. According to one estimate, more than 56,000 coseismic landslides were triggered in the seismic region [10]. The huge amount of loose source material drastically reduced the rainfall threshold for debris flows initiation compared to the period before the earthquakes and thus increased the probability of the outbreak of debris flows $[1,11,12]$.
This increase of the frequency and magnitude of postseismic debris flows and consequent potential river blocking received much attention. The feature and magnitude of tributary gullies and grain size of materials are important factors for debris flow-induced river blocking [13]. In 1991, the relationship between channel conditions and river blocking was theoretically investigated [14]. The entry angle, discharge ratio to the main stream, and volumes of debris entering into the main stream proved to be important factors for the formation of river blockings $[15,16]$. In order to measure the extent of river blocking, the runout momentum of debris flow as nondimensional factor was chosen [17]. Combined with basic characteristics of debris flow-induced river blocking, the possibility of river blocking was calculated [18]. Based on large-scale field experiments and equilibrium of mass in dynamic equations, the determination criteria of river blocking were proposed [19]. In general, the previous studies analyzing the factors influencing the blocking of rivers by debris flows used either empirical or physical experimental methods, but no numerical simulations. 


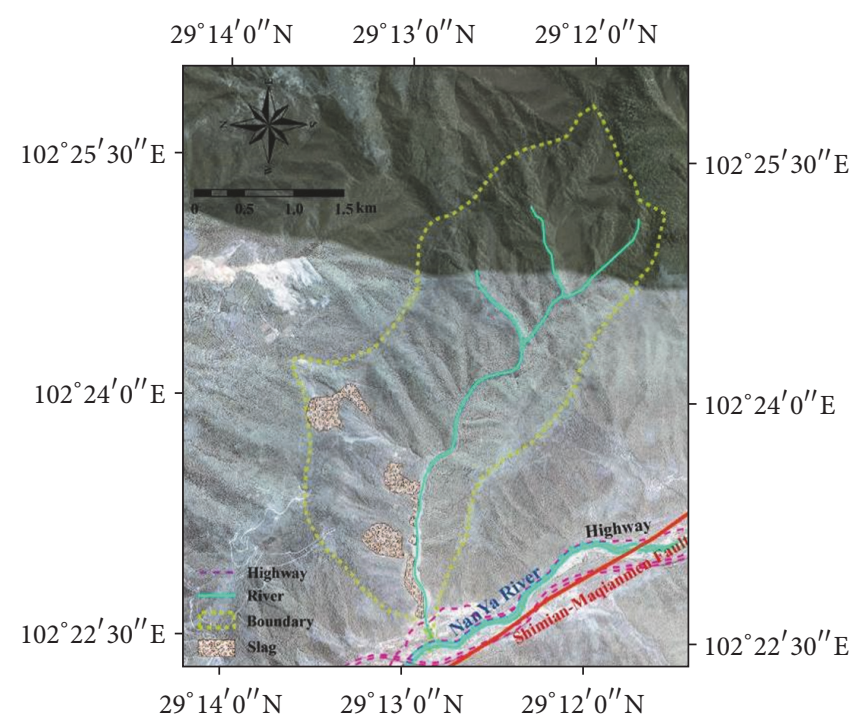

(a)

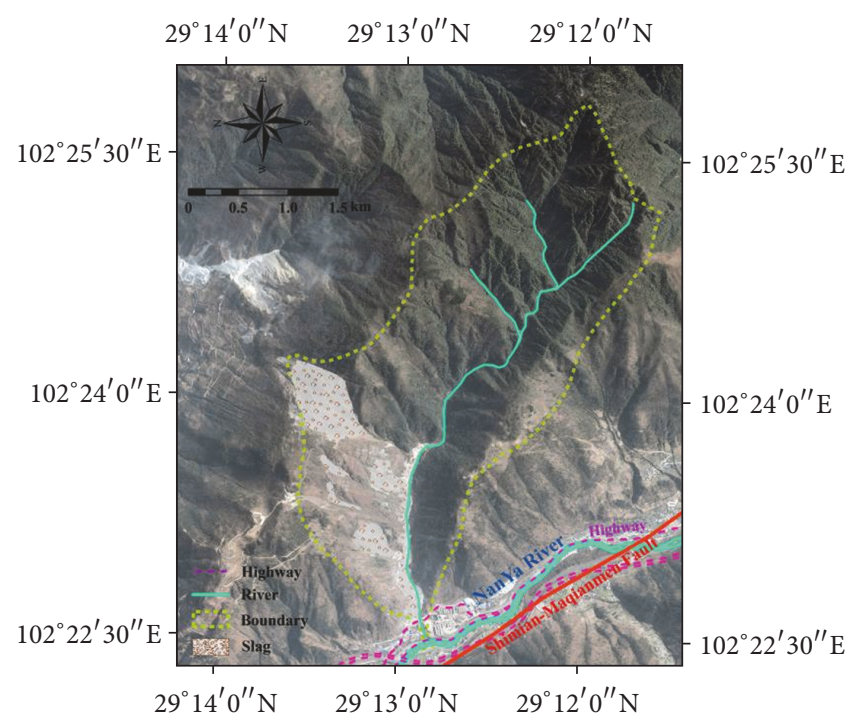

(b)

FIgURE 1: The slag distribution characteristic of contrast image in Guangyuanbao debris flow ((a) Spot 5 images taken on 18 March 2011 ; (b) Spot 5 images taken on 23 February 2015).

On July 04, 2013, an intense rainfall struck the Nanya River in Shimian city and triggered the Guangyuanbao debris flows on its right bank. Loose materials rushed into the river together with the debris flow, causing blocking of the Nanya River over a large area. This debris flow changed the channel direction and destroyed the houses and bridges, posing a danger to the local people. Some studies have been done on the formation mechanism, the hazard, and consequences of the Guangyuanbao debris flow. Ni et al. [20] analyzed the initiation mechanism and the dynamic characteristics of the Guangyuanbao debris flow and proposed mitigation measures for debris flows initiated by continuous torrential rainfall. Chang et al. [12] carried out field studies on material distribution, movement characteristics, and erosion intensity. The results showed that the abundant solid materials in the Shimian County produced a high potential for debris flow initiation and consequent river blocking caused by intense rainfalls and steep slopes. Based on a central finite difference method and non-Newtonian fluid model (Flo-2D), we created a debris flow numerical model to predict the mechanics of river blocking under various rainfall conditions. Recommendations are proposed to improve the debris flow mitigation and prevention.

\section{Study Area}

The studied Guangyuanbao debris flow is located at the right bank of the Nanya River, in the southeast of the Shimian County, Yaan City (adjoining the intense seismic region). During July 04, 2013, the total amount of accumulated rainfall reached $80.6 \mathrm{~mm}$ during 24 hours and caused debris flows which partly blocked the Nanya River. This led to a change of its channel, destroying houses and the G108 national highway, and cutting the lifeline to Shimian County. A contrast of the SPOT5 images taken on 18 March 2011 (before "7.04" debris flow) with the SPOT5 images taken on 23 February 2015 (after "7.04" debris flow) indicates that the asbestos slag area increased from $39.37 \times 10^{4} \mathrm{~m}^{2}$ to $66.16 \times 10^{4} \mathrm{~m}^{2}$, as shown in Figure 1.

The climate of Guangyuanbao gully is usually affected with an annual average temperature of $11.0-18.0^{\circ} \mathrm{C}$. With a largest daily rainfall of $300 \mathrm{~mm}$, the average annual rainfall is $1200 \mathrm{~mm}$. The precipitation is concentrated between August and October which account for $80 \%$ of the annual rainfall. The Nanya River is a fist-level stream with an average elevation of $3670 \mathrm{~m}$, total length of $78 \mathrm{~km}$. The exposed strata are mainly composed of intrusive rocks, colluvial layers, quaternary alluvium and debris flow deposits. From geological map, quaternary and Sinian formations are mainly outcropped in the Guangyuanbao debris flow. Another kind of quaternary sediments is asbestos slag, which were located on both sides of the debris flow gully. Based on ShimianMaqianmen fault distribution, the debris flows belong to an active seismic area. As a result, the bedrock is severely weathered and crushed with many landslides and rock falls.

\section{Methodology}

After the Wenchuan and Lushan earthquake, many loose solid materials were produced in the Guangyuanbao gully. The field investigation showed that the main source components for debris flows are landslide material and channel deposits. The main gully of the Guangyuanbao debris flow is $6.8 \mathrm{~km}$ long with an area of $9.3 \mathrm{~km}^{2}$. The highest altitude of the debris flow is $2870 \mathrm{~m}$ on ridges and the lowest altitude is $920 \mathrm{~m}$ at the outlet to the Nanya River. The relative elevation difference is $1950 \mathrm{~m}$. Upstream channel section and each tributary debris flow are relatively narrow, with a steep longitudinal slope. As observed in the field survey, there were more than thirty material sources with a total volume 
TABLE 1: Typical cross-section parameters in Guangyuanbao debris flow.

\begin{tabular}{|c|c|c|c|c|c|c|c|c|c|c|}
\hline Parameters & $\begin{array}{c}R \\
(\mathrm{~m})\end{array}$ & $\begin{array}{c}L \\
(\mathrm{rad})\end{array}$ & $\begin{array}{l}P_{0.05} \\
(\%)\end{array}$ & $\begin{array}{l}P_{2} \\
(\%)\end{array}$ & $\begin{array}{c}R_{v} \\
\left(\mathrm{~g} / \mathrm{cm}^{3}\right)\end{array}$ & $\begin{array}{c}R_{0} \\
\left(\mathrm{~g} / \mathrm{cm}^{3}\right)\end{array}$ & $\begin{array}{c}D_{50} \\
(\mathrm{~mm})\end{array}$ & $\begin{array}{c}D_{10} \\
(\mathrm{~mm})\end{array}$ & $\begin{array}{c}A^{\prime} \\
\left(\mathrm{m}^{2}\right)\end{array}$ & $\begin{array}{l}T \\
(\mathrm{~s})\end{array}$ \\
\hline $\begin{array}{l}\text { Cross-section of } \\
\text { main channel }\end{array}$ & 2.1 & 0.23 & 3.9 & 39.1 & 2.0 & 1.5 & 5.0 & 0.75 & 42.0 & 3600 \\
\hline
\end{tabular}

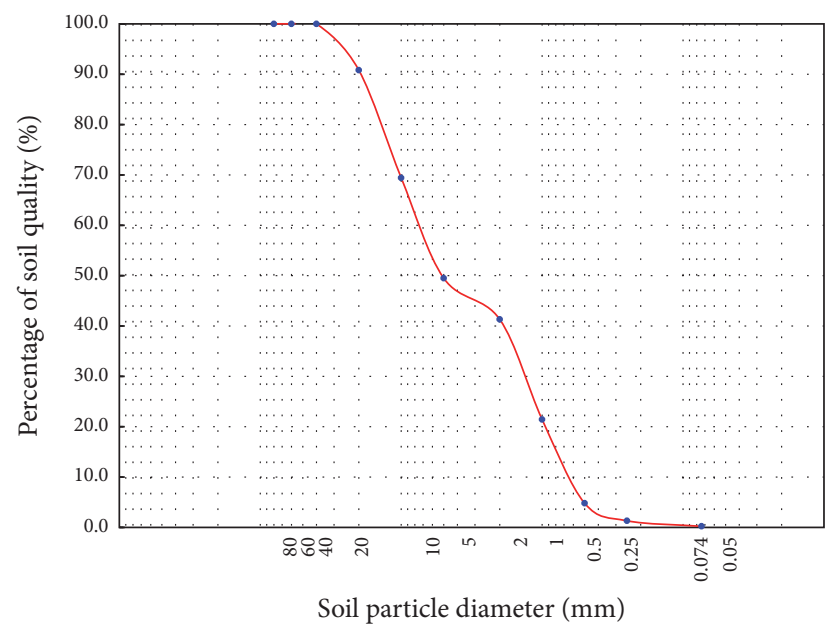

Figure 2: Particle grading curve of Guangyuanbao debris flow.

of $313.7 \times 10^{4} \mathrm{~m}^{3}$. The total asbestos mine volume reached $21.60 \times 10^{4} \mathrm{~m}^{3}$ and about $10.80 \times 10^{4} \mathrm{~m}^{3}$ was part of the Guangyuanbao debris flow (Figure 1). The steep slopes are around $45^{\circ}$ and may reach $70^{\circ}$ or larger in the middleupper part of the stream. The channel gradient is also large, especially in the upper part of the main stream and tributary streams where the gradient is more than $236 \%$. The steep slopes and steep channel gradients contributed to high runoff concentrations in combination with the presence of a lot of loose materials, mainly from the coseismic landslides, were beneficial for the development of debris flows. Debris flow increased in volume in its way down the slope due to intensive erosion of the channel and its sides and because of entrainment of source material, which partly blocked the channels. Debris flows could be initiated also through partly reactivation and fluidization of coseismic landslides and asbestos mine slag, which became saturated and transferred through intensive rainfall.

The Yaan City suffered from heavy rainfalls during July $3-4,2013$. The largest hourly rainfall intensity recorded was $36.6 \mathrm{~mm} / \mathrm{h}$ and the total antecedent rainfall from 18:00 to 21:00 when the debris flow which occurred was $60 \mathrm{~mm}$. The steep channel gradients somewhere can reach $600 \%$ which provided a large transport capacity of the debris flow and thus large amounts of gravels were deposited in the lower part of the channel and upper edge of the accumulation zone. Figure 2 shows the particle grading curve of the gully. It is shown that $39 \%$ of particles had diameters larger than $2 \mathrm{~mm}$ and $4 \%$ had diameters smaller than $0.05 \mathrm{~mm}$. Based on the field investigation, a large number of mud balls proved that it belongs to a viscous debris flow. Using following formula, this gully can be calculated as $2.0 \mathrm{KN} / \mathrm{m}^{3}$ [21]

$$
R_{D}=P_{0.05}{ }^{0.35} P_{2} R_{V}+R_{0}
$$

where $R_{D}$ represent the average density of Guangyuanbao debris flow, $\mathrm{g} / \mathrm{cm}^{3} ; P_{2}, P_{0.05}$ represent the percentages of coarse particles in a diameter larger than $2 \mathrm{~mm}$ and fine particles in a diameter smaller than $0.05 \mathrm{~mm}$, respectively; $R_{V}$ represent the average density of a viscous debris flow, $\mathrm{g} / \mathrm{cm}^{3}$; $R_{0}$ represent the minimum density, $\mathrm{g} / \mathrm{cm}^{3}$. The exact figures of these parameters are listed in Table 1.

The flow discharge, velocity, and total discharge are the main dynamic factors for debris flows. From the samples of average particle grading parameters and measured main cross-section of the gully, the static and dynamic condition can be calculated by (2) (see also Table 1).

$$
\begin{aligned}
V & =1.1 L^{1 / 3}(g R)^{1 / 2}\left(\frac{D_{50}}{D_{10}}\right)^{1 / 4}, \\
Q & =V A^{\prime}, \\
W_{c} & =0.26 T Q,
\end{aligned}
$$

where $V$ represent the average flow speed of the main crosssection, $\mathrm{m} / \mathrm{s}$; $L$ represent the slope of the debris flow at the cross-section location, (rad); $R$ represent the hydraulic radius, $(\mathrm{m}) ; g$ represent the gravity acceleration, $9.81 \mathrm{~m} / \mathrm{s}^{2} ; D_{10}$ represent the diameter of particles accounting for less than $10 \%$ of the total samples, (mm); $Q$ represent the flow discharge per second, $\mathrm{m}^{3} / \mathrm{s} ; D_{50}$ represent the median diameter of particles $(\mathrm{mm}) ; W_{c}$ represent the total quantity of sediments for one flow, $\mathrm{m}^{3} ; A^{\prime}$ represent the cross-sectional area of debris flow, $\mathrm{m}^{2}$. The values of these parameters taken in this research are listed in Table 1 . The $Q, V, W_{c}$ were determined as $206.45 \mathrm{~m}^{3} / \mathrm{s}, 4.92 \mathrm{~m} / \mathrm{s}$, and $12.88 \times 10^{4} \mathrm{~m}^{3}$, respectively. The yield stress of the debris flow can be calculated by the following equation [22]:

$$
\tau_{B}=R_{D} g h \sin \theta,
$$

where $\tau_{B}$ represent the yield stress, $\mathrm{Pa} ; h$ represent the maximum deposit thickness, $(h=6 \mathrm{~m}) ; R_{D}$ represent the density, $\mathrm{kg} / \mathrm{m}^{3} ; \theta$ is the slope; $\theta=13^{\circ}$. The yield stress represents the antierosion capacity of the debris flow against the river. The yield stress is a resistance term, in fact a cohesion term of the debris flow material. At higher driving stresses than the yield stress a Bingham material starts to flow and oppositely at lower driving stresses the debris flow will stop. The yield stress of the Guangyuanbao debris flow was 
TABLE 2: Parameter identification in the numerical simulation process.

\begin{tabular}{|c|c|c|c|c|}
\hline & $\begin{array}{l}\text { Solid volumetric } \\
\text { concentration }(-)\end{array}$ & $\begin{array}{l}\text { Amplification coefficient } \\
(-)\end{array}$ & $\begin{array}{l}\text { Yield strength } \\
\qquad(\mathrm{Pa})\end{array}$ & $\begin{array}{l}\text { Viscous coefficient } \\
\text { (Pa sec) }\end{array}$ \\
\hline & $\mathrm{C}_{V}$ & $\mathrm{BF}$ & $\tau_{y} /$ & $\eta$ \\
\hline $\begin{array}{l}\text { Guangyuanbao } \\
\text { debris flow }\end{array}$ & 0.6 & 2.5 & 4903 & 5704 \\
\hline
\end{tabular}

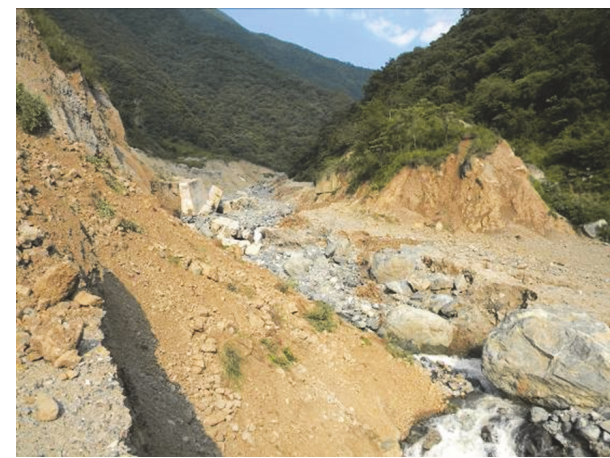

(a) Blocking of a landslide

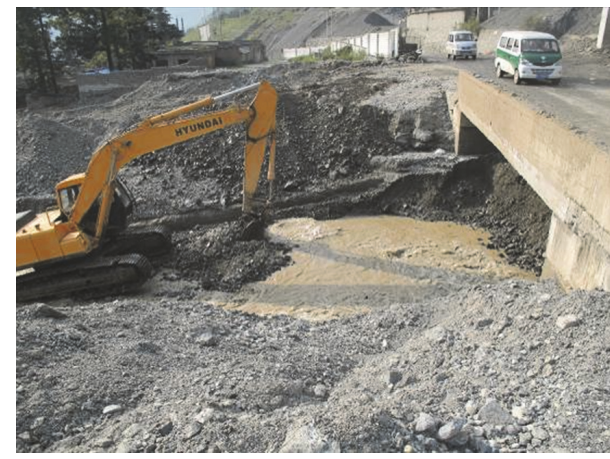

(c) Blocking of the bridge

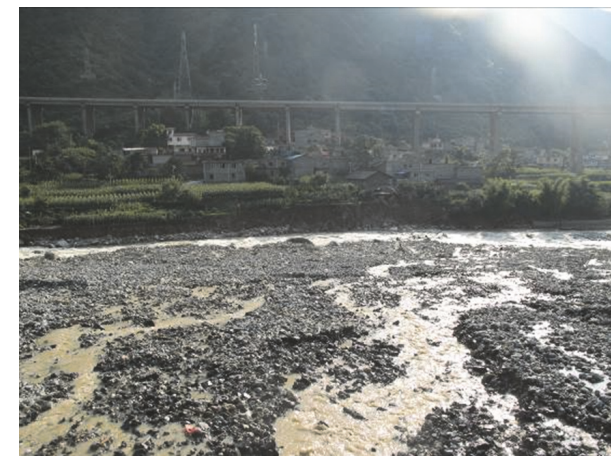

(b) Blocking of the debris flow

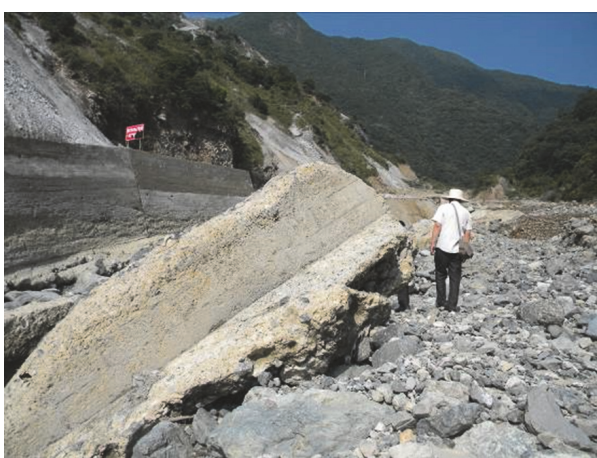

(d) Blocking of the channel

FIGURE 3: Blockage condition of the Guangyuanbao debris flow.

$2.14 \times 10^{4} \mathrm{~Pa}$, which was able to provide strong resistance against the erosion of the Nanya River. The Nanya River flowing from the north side of Yaan City has an average longitudinal slope of 38.\%o, an average annual discharge of $47.7 \mathrm{~m}^{3} / \mathrm{s}$, and maximum discharge of $200 \mathrm{~m}^{3} / \mathrm{s}$. Presently, the blocking situation of the Nanya River is shown in Figure 3(b).

\section{Results}

4.1. Numerical Simulation Parameters. The FLO-2D mathematical model was applied to simulate flow movement and damming for disaster reduction planning. Generally speaking, this model needs two parts: finite difference continuity and a dynamic-wave momentum equation. For the momentum balance equation the quadratic rheological model was adopted, including turbulent shear stress, cohesive yield stress, yield shear stress, and viscous shear stress:

$$
S_{f}=S_{\mathrm{td}}+S_{v}+S_{y}=\frac{n^{2} u^{2}}{h^{4 / 3}}+\frac{K \eta u}{8 r_{m} h^{2}}+\frac{\tau_{y}}{r_{m} h},
$$

where $S_{f}$ is the total friction slope; $S_{v}$ is the viscous slope; $S_{\mathrm{td}}$ is the turbulent-diffusion slope; $S_{y}$ is the yield slope; $n$ is Manning's roughness coefficient; $h$ is the debris flow accumulation depth; $K$ is an empirical flow resistance parameter; $u$ is the debris flow velocity; $r_{m}$ is the unit weight of the fluid; $\eta$ is the fluid viscosity; $\tau_{y}$ is the yield stress.

We used the geographic information system to produce a $2.5 \mathrm{~m}$ Digital Elevation Model from the 1:10,000 scale topographic map in order to obtain the topographic characteristics for the debris flow numerical simulation. Velocity and final deposit depths formed the most important output of the model. According to field investigation and laboratory tests, some numerical parameters were identified as listed in Table 2.

Debris flow discharges are related to the water flow discharges in Flo-2D. In order to obtain water flow discharges for three recurrence periods the calculation manual for storm floods in small and medium river basin for the Sichuan Province has been consulted. To calculate flood discharges, we selected rainfall intensities with a return period of 50, 


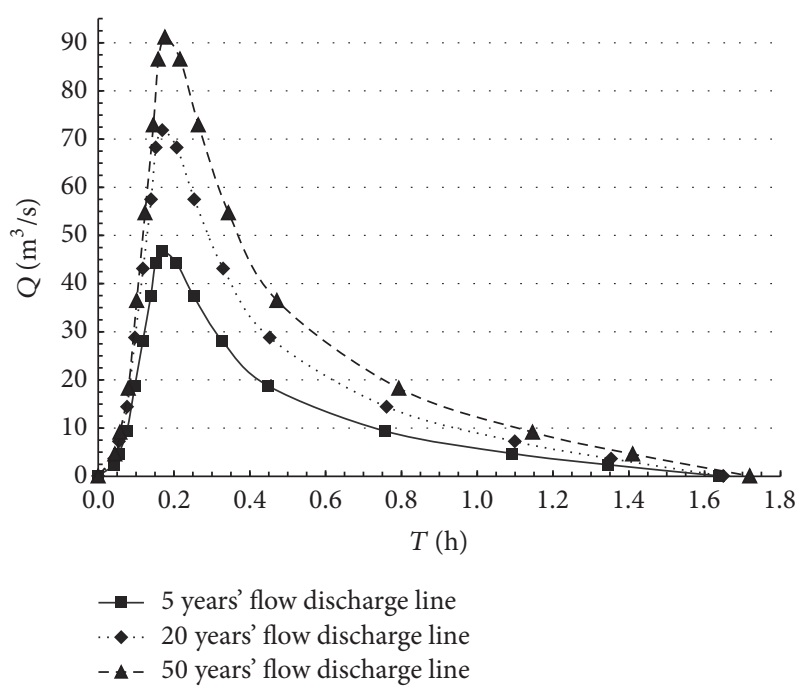

Figure 4: Water flow hydrograph of Guangyuanbao debris flow under different rainfall frequencies.

20 , and 5 years, respectively. The flood discharges were calculated using the rainfall data (duration and total amount) of the Guangyuanbao debris flow. Based on the "Specification for Geological Investigation of Debris Flow Stabilization in China," the flow process curves were obtained for these three rainfall return periods (Figure 4).

The volume concentration confirms the content of sediments in the debris flow and the water flow curve in the numerical model. The volume concentration is given by the volume of sediment material divided by the total volume,

$$
C_{V}=\frac{V_{W}}{V_{D}}
$$

where $C_{V}$ is the volume concentration of the debris flow, 0.6; $V_{D}$ the total volume of sediment material; and $V_{W}$ the volume of sediment material. The other simulation parameters such as amplification coefficient $(\mathrm{BF})$, yield strength $\left(\tau_{y}\right)$, and vicious coefficient $(\eta)$ were calculated by $(6)-(8)$, respectively.

$$
\begin{aligned}
\mathrm{BF} & =\frac{1}{C_{V}}, \\
\eta & =\alpha_{1} e^{\beta_{1} C_{v},} \\
\tau_{y} & =\alpha_{2} e^{\beta_{2} C_{v}},
\end{aligned}
$$

where $\alpha_{1}, \alpha_{2}, \beta_{1}$, and $\beta_{2}$ represent the coefficients for the calculation of $\tau_{y}$ and $\eta$. In this research, the experimental data of Zhan et al. [23] were used: $\alpha_{1}=0.811, \beta_{1}=13.72$, $\alpha_{2}=0.00462$, and $\beta_{2}=11.24$. Linking field investigation with physical experiment, a series of blocking river experiments were adopted. Figures 5(a) and 5(b) showed the debris flow completely and partly blocked rivers condition in the laboratory, which can provide series parameters of numerical simulation. Figure 5(c) is a conceptual diagram, for the blocking of a river which can be classified into three categories (Table 3).
TABLE 3: Division standard of river blocking.

\begin{tabular}{lc}
\hline Type & Classification criterion \\
\hline No blocking & $L \leq L_{1}$ \\
Partly blocking & $L_{1}<L<L_{1}+L_{2}$ \\
Completely blocking & $L \geq L_{1}+L_{2}$ \\
\hline
\end{tabular}

$L$ : distance of debris flow runout; $L_{1}$ : distance from apex to river; $L_{2}$ : river width.

4.2. Numerical Results and Validation. The runout characteristics of the Guangyuanbao debris flow under different rainfall return periods were simulated with FLO-2D. Figure 6(a) shows the different patterns of river blocking for the three return periods.

According to the "Calculation Manual of Storm Flood in Small and Medium River Basin in Sichuan Province," the "July 3-4, 2013," rainfall event in Guangyuanbao basin is equal to a rainfall with a return period of 20 years. Figure $6(\mathrm{~b})$ shows the spreading obtained by the numerical simulation of this event in relation to the observed deposition pattern [24]. The accuracy of the model simulation of the Guangyuanbao debris flow is given by

$$
A=\sqrt{\left(\frac{S_{O}}{S_{M}} \cdot \frac{S_{O}}{S_{N}}\right)} \times 100 \%,
$$

where $A$ represent the numerical result accuracy; $S_{N}$ represent the numerically predicted deposit range, $\mathrm{m}^{2} ; S_{M}$ represent the accumulation zone range measured in the field, $\mathrm{m}^{2} ; S_{O}$ represent the overlap region of the predicted and field measured deposit range, $\mathrm{m}^{2}$. The detailed parameter values are listed in Table 4 . The closer $A$ is to unity, the more accurate the numerical simulation results are. The numerical accuracy was $88.05 \%$ which is acceptable for numerical analysis (Figure 6(b)).

For the rainfall with 5 years' return period a small part of the debris flow material can enter the Nanya River, which will be taken away by the river current (i.e., no river blocking will occur). For the rainfall with a return period of 20 years, the debris flow will partly block the river. The numerical simulation results agree well with debris flow deposition fan caused by the "July 3-4, 2013," rainfall event. Under a 50 years' rainfall frequency, the debris flow led to complete river blocking. The direct impact force and deposit depth form a serious threat to the bridge, houses, and G108 national highway.

\section{Conclusions and Discussions}

Series of the earthquakes produced large amounts of landslides which in the period partly transformed into debris flows, triggered by extreme rainfalls. The Guangyuanbao debris flow is a good example of such a reactivated coseismic landslide. This debris flow blocked the Nanya river and flooded houses and streets, posing a serious danger to the proper safety and life of local residents. This study applied FLO-2D to simulate Nanya river blocking and presented the formation, movement, accumulation, and degree of river 
TABLE 4: Precision validation of numerical simulation in accumulation range.

\begin{tabular}{|c|c|c|c|c|}
\hline & \multicolumn{4}{|c|}{ Accumulation range } \\
\hline & Measured $/ 10^{3} \mathrm{~m}^{2}$ & Predicted $/ 10^{3} \mathrm{~m}^{2}$ & Overlap $/ 10^{3} \mathrm{~m}^{2}$ & Accuracy $/ \%$ \\
\hline $\begin{array}{l}\text { Guangyuanbao } \\
\text { debris flow }\end{array}$ & 5.69 & 6.13 & 5.20 & 88 \\
\hline
\end{tabular}

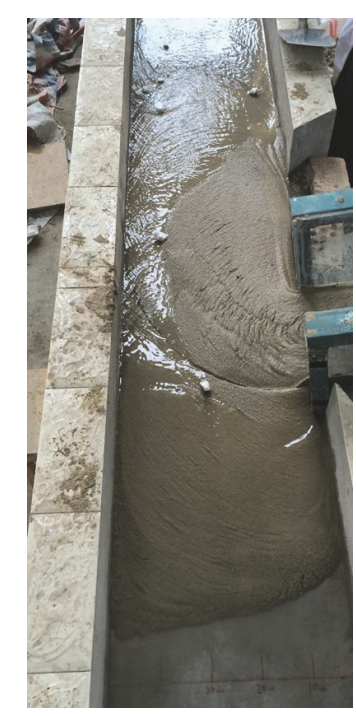

(a) Complete blocking of the river

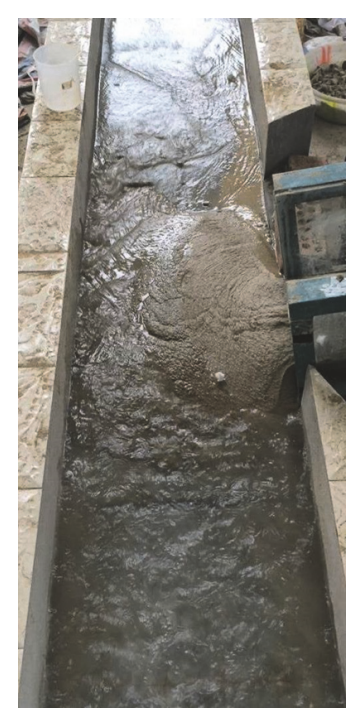

(b) Partial blocking of the river

Diagram of physical simulation for debris flow blocking the river

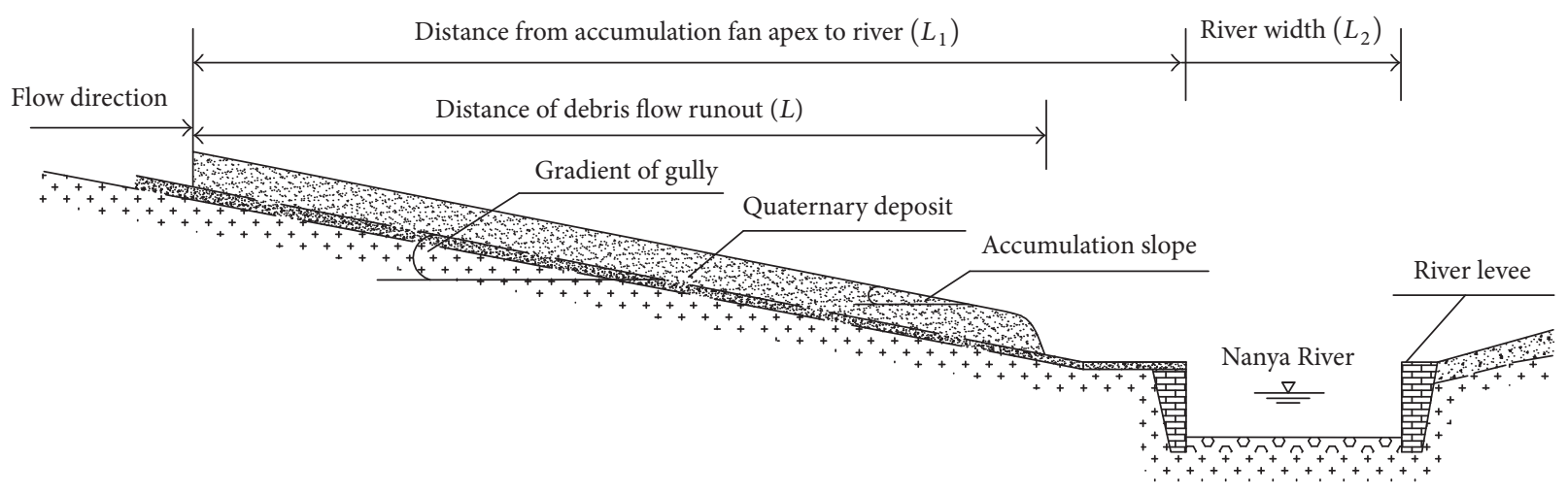

Granite

Probale bed

Quaternary deposit
監 Mortared rubble

Actumulation zone

(c) Cross-section of the Guangyuanbao gully

FIGURE 5: Different degrees of blocking the main river in debris flow experiments.

blocking of Guangyuanbao debris flow under various rainfall frequencies. Comparing ordinary experience model, the advantage of FLO-2D numerical simulations was that it can intuitively and clearly respond to the type of river blocking. The numerical simulations were validated against the field survey and remote sensing interpretation of the accumulation fan of the Guangyuanbao debris flow which occurred on July 3-4, 2011.
According to the field survey and physical experiments, influence factors of the formation and movement of Guangyuanbao debris flow were defined, including sediments source, topographic condition, hydrological regime, and static-dynamic conditions. The Wenchuan earthquake provided large amounts of landslides and rock falls as sediments source for Guangyuanbao debris flow. The total mass reaches $313.7 \times 10^{4} \mathrm{~m}^{3}$ before the debris flow; among 


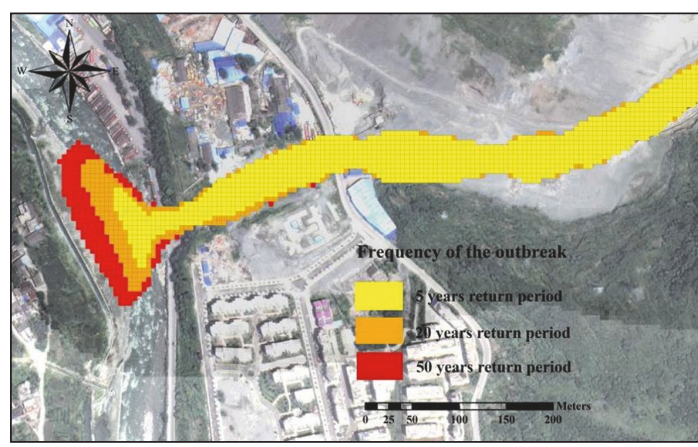

(a) Numerical results of Guangyuanbao debris flow

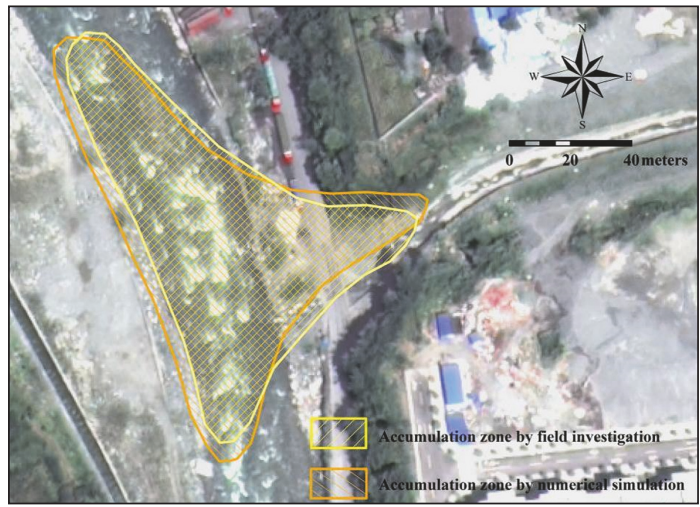

(b) Validation results of Guangyuanbao debris flow

FIGURE 6: Numerical results of the Guangyuanbao debris flow under various rainfall frequencies (a) and its validation against a field survey of the deposition fan (b).

them about $12.88 \times 10^{4} \mathrm{~m}^{3}$ of the mudslides rushed out and rushed away by the debris flow. The continuous heavy rainfalls reactivated the loose coseismic landslide material, which transformed into the Guangyuanbao debris flow and activated the erosion in the channel increasing its mass, which led to partial blocking of the Nanya River. The Guangyuanbao debris flow had a maximum flow speed of $4.9 \mathrm{~m} / \mathrm{s}$, a total volume of sediments of $12.88 \times 10^{4} \mathrm{~m}^{3}$, a peak flow discharge of $206 \mathrm{~m}^{3} / \mathrm{s}$, and a yield strength of $4.903 \mathrm{kpa}$.

The range in spreading of the accumulation zone of the Guangyuanbao debris flow was simulated with FLO-2D for different rainfall frequencies. The prediction of the spreading of the fan deposit was validated against the observed spreading of the deposition fan. The numerical simulation has an accuracy of $88.05 \%$ which meets the requirement for numerical analysis.

The numerical simulation results for Guangyuanbao debris flows under different rainfall intensities indicate that the rainfall under 5 years' return period is able to bring the loose materials just a bit outside the gully mouth. A rainfall under 20-year return period will lead to a partial blockage of the Nanya River while a complete blockage may occur for a rainfall event under 50-year return period.

\section{Conflicts of Interest}

The authors declare that they have no conflicts of interest.

\section{Acknowledgments}

The research was supported by the National Natural Science Foundation of China (no. 41702312), Sichuan Provincial Department of Education of China (17ZB0054), the Fund for International Cooperation (NSFC-RCUK_NERC), Resilience to Earthquake-Induced Landslide Risk in China (Grant no. 41661134010), and the financial assistance provided by China Geology Survey (Project no. [2014]-05-01).

\section{References}

[1] N. Caine, "The rainfall intensity-duration control of shallow landslides and debris flows," Geografiska Annaler, Series A: Physical Geography, vol. 62, no. 1-2, pp. 23-27, 1980.

[2] D. Alexander, "Urban landslides," Progress in Physical Geography, vol. 13, no. 2, pp. 157-189, 1989.

[3] M. Hürlimann, R. Copons, and J. Altimir, "Detailed debris flow hazard assessment in Andorra: a multidisciplinary approach," Geomorphology, vol. 78, no. 3-4, pp. 359-372, 2006.

[4] F. C. Dai, C. Xu, X. Yao, L. Xu, X. B. Tu, and Q. M. Gong, "Spatial distribution of landslides triggered by the $2008 \mathrm{Ms} 8.0$ Wenchuan earthquake, China," Journal of Asian Earth Sciences, vol. 40, no. 4, pp. 883-895, 2011.

[5] T. Gorum, X. Fan, C. J. van Westen et al., "Distribution pattern of earthquake-induced landslides triggered by the 12 May 2008 Wenchuan earthquake," Geomorphology, vol. 133, no. 3-4, pp. 152-167, 2011.

[6] C. Tang, G. Ma, M. Chang et al., "Landslides triggered by the 20 April 2013 Lushan earthquake, Sichuan Province, China," Engineering Geology, vol. 187, pp. 45-55, 2015.

[7] K. M. Scott, J. W. Vallance, N. Kerle, J. L. Macías, W. Strauch, and G. Devoli, "Catastrophic precipitation-triggered lahar at Casita volcano, Nicaragua: Occurrence, bulking and transformation," Earth Surface Processes and Landforms, vol. 30, no. 1, pp. 59-79, 2005.

[8] C.-N. Liu, H.-F. Huang, and J.-J. Dong, "Impacts of september 21, 1999 Chi-Chi earthquake on the characteristics of gully-type debris flows in central Taiwan," Natural Hazards, vol. 47, no. 3, pp. 349-368, 2008.

[9] C. L. Shieh, Y. S. Chen, Y. J. Tsai, and J. H. Wu, "Variability in rainfall threshold for debris flow after the Chi-Chi earthquake in central Taiwan, China," International Journal of Sediment Research, vol. 24, no. 2, pp. 177-188, 2009.

[10] C. Tang, J. Zhu, M. Chang, J. Ding, and X. Qi, "An empiricalstatistical model for predicting debris-flow runout zones in the Wenchuan earthquake area," Quaternary International, vol. 250, pp. 63-73, 2012.

[11] B. Yu, "Study on the method for deposition depth calculation of debris flow with different densities," Journal of Disaster Prevention and Mitigation Engineering, vol. 30, no. 2, pp. 207211, 2010.

[12] M. Chang, C. Tang, D.-D. Zhang, and G.-C. Ma, "Debris flow susceptibility assessment using a probabilistic approach: A case study in the Longchi area, Sichuan province, China," Journal of Mountain Science, vol. 11, no. 4, pp. 1001-1014, 2014. 
[13] Z. Cheng, C. Dang, J. LIU, and Y. Gong, "Experiments of debris flow damming in southeast tibet," Earth Science Frontiers, vol. 14, no. 6, pp. 181-185, 2007.

[14] B. F. Zhou, D. J. Li, and D. F. Luo, Debris Flow Prevention Guide, Science Press, Beijing, China, 1991.

[15] J. S. O’Brien, P. Y. Julien, and W. T. Fullerton, “Two-dimensional water flood and mudflow simulation," Journal of Hydraulic Engineering, vol. 119, no. 2, pp. 244-261, 1993.

[16] Z. X. Guo, S. Y. Cao, X. N. Liu, and D. Fang, "Experimental study on parameters affecting the river blocking due to debris flow," Journal of Hydraulic Engineering, vol. 11, pp. 39-45, 2004.

[17] C.-G. Chen, L.-K. Yao, C.-R. Liu, and C. Du, "Study on conditions of river-blocking due to debris flow," Journal of Hydraulic Engineering, vol. 44, no. 6, pp. 648-656, 2013.

[18] J. S. Zhang and H. Xie, "Calculation of the possibility of river blocking due to debris flow in the upper reaches of Nanya River," Resources and Environment in the Yangtze Basin, vol. 17, no. 4, pp. 651-655, 2008.

[19] CR. Liu and C. Du, "Characteristic and criteria of debris flow partially blocking big river," Journal of Chongqing Jiaotong University, vol. 33, no. 1, pp. 79-84, 2014.

[20] H. Ni, W. Zheng, Z. Song, and W. Xu, "Catastrophic debris flows triggered by a 4 July 2013 rainfall in Shimian, SW China: formation mechanism, disaster characteristics and the lessons learned," Landslides, vol. 11, no. 5, pp. 909-921, 2014.

[21] C. Tang and J. T. Liang, "Characteristics of debris flows in Beichuan epicenter of the Wenchuan earthquake triggered by rainstorm on September 24, 2008," Journal of Engineering Geology, vol. 16, no. 6, pp. 751-758, 2008.

[22] M. Chang, C. Tang, H. Ni, and Y. Qu, "Evolution process of sediment supply for debris flow occurrence in the Longchi area of Dujiangyan City after the Wenchuan earthquake," Landslides, vol. 12, no. 3, pp. 611-623, 2015.

[23] Q. D. Zhan, C. Y. Yu, and Y. D. Wu, "The preliminary study of sand concentration on the rheological parameters of the sand bodies," in Proceedings of the First Debris Flow Symposium Proceedings, pp. 179-190, 1997.

[24] M. Chang, C. Tang, T. W. J. van Asch, and F. Cai, "Hazard assessment of debris flows in the Wenchuan earthquake-stricken area, South West China," Landslides, pp. 1-10, 2017. 

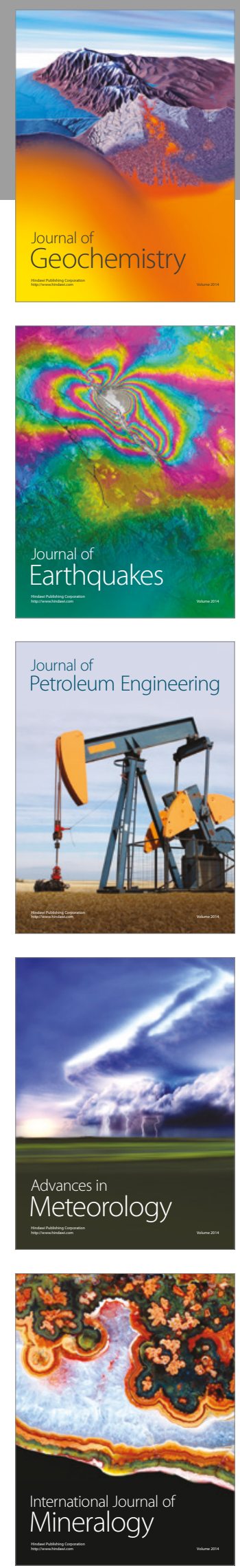
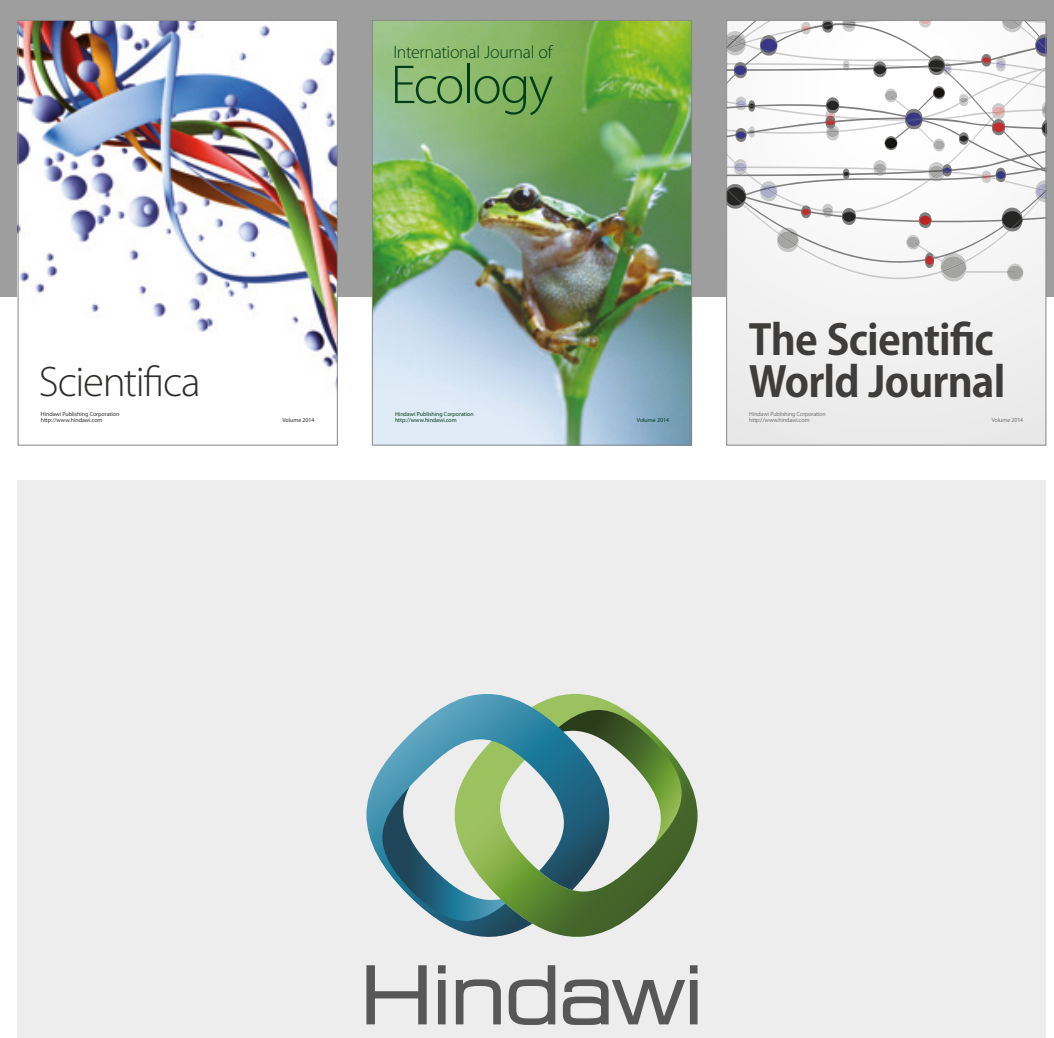

Submit your manuscripts at

https://www.hindawi.com
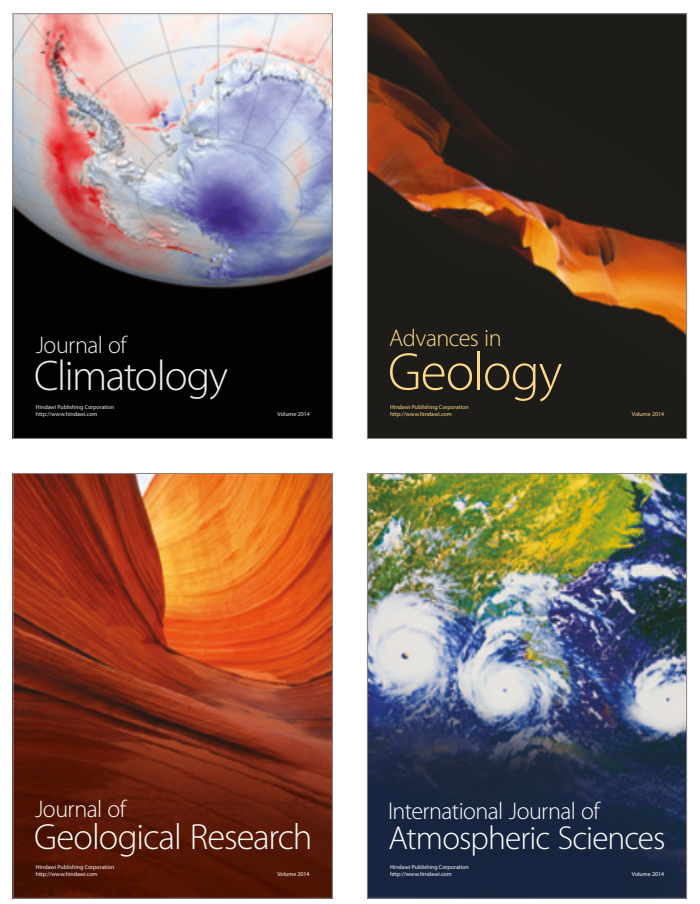

The Scientific

World Journal
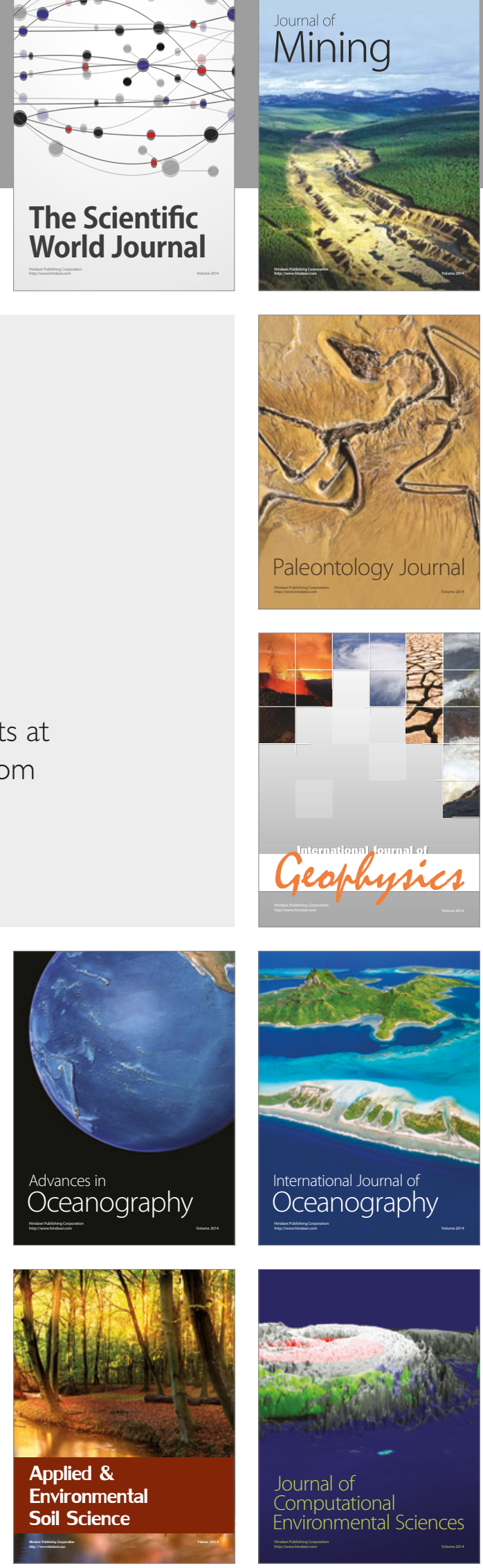